\title{
Building Allied Health Research Capacity at a Regional Australian Hospital: A Follow-up Study.
}

\section{Tilley Pain}

Townsville Hospital and Health Service and James Cook University, Townsville, tilley.pain@health.qld.gov.au

Michelle Petersen

Townsville Hospital and Health Service, gmpetersen@y7mail.com

Malindu Fernando

James Cook University, Townsville and School of Clinical Sciences, Queensland University of Technology, Brisbane, malindu.fernando@my.jcu.edu.au

Follow this and additional works at: https://nsuworks.nova.edu/ijahsp

Part of the Medicine and Health Sciences Commons

\section{Recommended Citation}

Pain T, Petersen M, Fernando M. Building Allied Health Research Capacity at a Regional Australian Hospital: A Follow-up Study.. The Internet Journal of Allied Health Sciences and Practice. 2018 Jan 01;16(4), Article 8.

This Manuscript is brought to you for free and open access by the College of Health Care Sciences at NSUWorks. It has been accepted for inclusion in Internet Journal of Allied Health Sciences and Practice by an authorized editor of NSUWorks. For more information, please contact nsuworks@nova.edu. 


\section{Building Allied Health Research Capacity at a Regional Australian Hospital: A Follow-up Study.}

\section{Abstract \\ Purpose}

This study determined if research experience increased among allied health professionals (AHPs) at a regional tertiary hospital following a research capacity building initiative.

\section{Methods}

A cross sectional electronic survey was used to collect data from allied health professionals on their research experience, research support needs, enablers and barriers to research and their perceptions regarding benefits of research. A baseline survey was conducted in 2011 which was compared to a follow up survey in 2015. Comparison of variables between the two surveys used Chi squared tests.

\section{Results}

The response rate for the 2011 survey was $43 \%(n=248)$ while the 2015 survey achieved a $37 \%$ response rate $(n=234)$. There was a significant increase in allied health professionals research experience as well as need for research support between the 2011 and 2015 surveys in many (but not all) activities on the research continuum. Time availability was the greatest barrier and the perceived benefit of research was to improve clinical care.

\section{Conclusions}

This study demonstrates a significant increase in allied health professionals research experience over the four years of capacity building. However, the increase has not reached the level where it is recorded by traditional research outcome measures such as publication. The greatest barrier to allied health professionals conducting research is time. Therefore, investment in clinician-researcher career pathways may increase research capacity of allied health practitioners to increase publication output. The implication of this research is that allied professionals' research profile is unlikely to increase without significant input of time or resources to allow them to conduct research.

\section{Author Bio(s)}

Tilley Pain, Medical Laboratory Scientist, PhD.Tilley is the research fellow for allied health professionals at a regional tertiary hospital in Australia.

Michelle Petersen, Speech Pathologist. Michelle is a senior speech pathologist now working in private practice.

Malindu Fernando, Podiatrist, PhD. Mal is a podiatrist with a specific interest in high risk diabetic foot.

\section{Acknowledgements}

We would like to acknowledge the Health Practitioner staff of Townsville Hospital and Health Service for participating in the survey, to Karen Phillips, Director of Allied Health for hosting the Research Officers (MF, MP) and to the THHS Study Education and Research Trust Account (SERTA) for funding the project. 


\title{
TUAHSP \\ The Internet Joutnal of Allied Health Sciences and Practice Dedicated to allied health professional practice and education
}

Vol. 16 No. 4 ISSN 1540-580X

\section{Building Allied Health Research Capacity at a Regional Australian Hospital: A Follow-up Study}

\author{
Tilley Pain 1,2 \\ Michelle Petersen ${ }^{1}$ \\ Malindu Fernando 2,3
}

1. Townsville Hospital and Health Service

2. James Cook University

3. Queensland University of Technology

Australia

\begin{abstract}
Purpose: This study determined if research experience increased among allied health professionals (AHPs) at a regional tertiary hospital following a research capacity building initiative. Methods: A cross sectional electronic survey was used to collect data from allied health professionals on their research experience, research support needs, enablers and barriers to research and their perceptions regarding benefits of research. A baseline survey was conducted in 2011 which was compared to a follow up survey in 2015. Comparison of variables between the two surveys used Chi squared tests. Results: The response rate for the 2011 survey was $43 \%$ ( $n=248)$ while the 2015 survey achieved a $37 \%$ response rate $(n=234)$. There was a significant increase in allied health professionals research experience as well as need for research support between the 2011 and 2015 surveys in many (but not all) activities on the research continuum. Time availability was the greatest barrier and the perceived benefit of research was to improve clinical care. Conclusions: This study demonstrates a significant increase in allied health professionals research experience over the four years of capacity building. However, the increase has not reached the level where it is recorded by traditional research outcome measures such as publication. The greatest barrier to allied health professionals conducting research is time. Therefore, investment in clinician-researcher career pathways may increase research capacity of allied health practitioners to increase publication output. The implication of this research is that allied professionals' research profile is unlikely to increase without significant input of time or resources to allow them to conduct research.
\end{abstract}

\section{INTRODUCTION}

Many initiatives have been trialled to increase the research capacity of allied health professionals (AHPs) in Australia over the last decade. One example was the Allied Health Professions Office of Queensland (AHPOQ) state-wide research capacity building (RCB) framework embedded within an industrial agreement established in 2008. The framework included limited funding for Research Fellow (RF) positions and competitive grant funding to initiate research. ${ }^{1}$ At the local level, RFs were employed under the framework within individual Hospital and Health Services (HHS) and provided a variety of activities to increase allied health research. For example, activities provided by the RF at our study site, the Townsville HHS (THHS), included research education, mentoring of individual researchers, and marketing a "Doctoral Cohort" program at the local university where PhD students access face to face education of research methodologies as block subjects. Other activities undertaken by the RF included developing and chairing a research special interest group and promoting and celebrating research achievements (e.g. printed annual report, annual research award, and publicity in the internal newsletter). Organisational RCB by the HHS at the study site included establishing a research support unit, providing internal grants, employing a Director of Research, and building research office space.

C Internet Journal of Allied Health Sciences and Practice, 2018 
Building research capacity within health services is important as it can provide evidence on which to base policy and practice decisions. ${ }^{2}$ Current research activity by AHPs at THHS is predominantly to improve care delivered by the respective allied health disciplines. This focus of local AHP research fits with the concept that RCB is a funded, dynamic intervention operationalised through a range of activities and levels to achieve objectives in research over the long-term, with aspects of social change as the ultimate outcome. ${ }^{3}$ Therefore, initiatives supporting the research efforts of motivated staff using training, infrastructure and quarantined time achieve better outcomes for research capacity building investment. ${ }^{4}$ These strategies and concepts have now been in place for AHPs at THHS since 2010. To measure the impact of these efforts, a baseline survey of research capacity was conducted in 2011.

Results from the baseline survey in 2011 showed AHPs had high interest but little experience in research at our study site. ${ }^{5-7}$ Research activity was impeded by lack of confidence, limited knowledge and lack of skills by clinicians to do research. ${ }^{7}$ An interesting finding was that the amount of support required for activities along the research continuum were inversely related to the clinician's level of research experience. ${ }^{6}$ Furthermore, research activity was highest in the centres with most research resources, such as a RF, leading to the conclusion that successful research capacity building required dedicated personnel. ${ }^{5}$ The RCB activities have continued in the intervening years leading to question whether the efforts have achieved the aim of increasing research production by AHPs since 2011. Therefore, the aim of this study was to determine whether AHPs' research experience has increased since 2011.

\section{METHODS}

Study design: A cross sectional electronic survey was used as the main data collection tool for this study. The survey link was initially electronically sent in November 2014 and followed up weekly in 2015 with reminder emails. The survey closed in March 2015. Ethics approval was obtained from the THHS Human Research Ethics Committee (Approval number HREC/15/QTHS/23) prior to the study.

Participants: Eligible participants were all staff classified as Health Practitioners (HPs) currently working for the THHS, a regional Hospital and Health Service in northern Queensland. Participants were identified and contacted via an email address list maintained by the organisation's Workforce Development Officer. The baseline survey achieved a $43 \%$ response rate amongst AHPs in 2011. It was calculated 265 participants were required to complete the follow-up survey to achieve a similar response rate. The number of allied health staff working for the THHS during the second survey period was 618 (10 th February 2015). HPs employed as medical laboratory scientists were not included as they were not accessible via the same email system.

Data collection tool: Survey monkey (SurveyMonkey Inc, San Mateo, California, US, www.surveymonkey.com) questionnaires were used to collect data in both surveys. The original survey was modified to capture additional information regarding motivators for participating in research. The data collected included demographic variables (age, gender, work-place characteristics), and level of research experience and support needs. Participants were also asked to rate the benefits of research and research barriers and enablers. All responses were set out as 5-point Likert scales.

Data analysis: Data from Survey Monkey were exported to an Excel spreadsheet and modified into appropriate variables prior to analysis. Statistical Package for the Social Sciences (SPSS) 22.0 for Windows (SPSS Inc., Chicago, IL, USA) was used for the statistical comparisons of demographic characteristics.

Data from the 2011 and 2015 surveys were collected from the individual databases and combined for comparison in SPSS. Demographic data were presented using descriptive statistics and all comparisons between the 2011 and 2015 surveys were analysed using Pearson's Chi Squared tests. If $p$ values were less than 0.05 , a result was considered statistically significant.

\section{RESULTS}

Demographics

The response rate for the 2011 survey was $43 \%$ ( $n=248)$ while the 2015 survey achieved a $37 \%$ response rate $(n=234)$. Females comprised $76 \%$ of the workforce in both the 2011 and 2015 surveys. None of the respondents identified as Aboriginal or Torres Strait Islander in the 2015 survey whereas $3 \%$ did so in the original survey. Twentyeight different allied health disciplines responded to the 2011 survey and twenty to the 2015 survey (Table 1).

(C) Internet Journal of Allied Health Sciences and Practice, 2018 
Table 1: Comparison of the demographic characteristics collected on participants in the 2011 and 2015 surveys.

\begin{tabular}{|l|c|c|}
\hline Demographic Variable & $\mathbf{2 0 1 1}$ & $\mathbf{2 0 1 5}$ \\
\hline Response rate & $248 / 580=43 \%$ & $234 / 641=37 \%$ \\
\hline Females & $76 \%$ & $76 \%$ \\
\hline Age (range) & $32(22$ to 67$)$ & $36(20$ to 74$)$ \\
\hline Work setting & & \\
$\quad$ Acute (hospital based) & $60 \%$ & $65 \%$ \\
Community (incl. outreach) & $20 \%$ & $16 \%$ \\
\hline Work role & & \\
Clinical & $61 \%$ & $65 \%$ \\
$\quad$ Management & $19 \%$ & $16 \%$ \\
\hline Indigenous & $3 \%$ & $0 \%$ \\
\hline Discipline & $15 \%$ & $22 \%$ \\
Occupational therapy & $14 \%$ & $13 \%$ \\
Social work & $13 \%$ & $15 \%$ \\
Physiotherapy & $58 \%$ & $50 \%$ \\
Others & \multicolumn{2}{|}{} \\
\hline
\end{tabular}

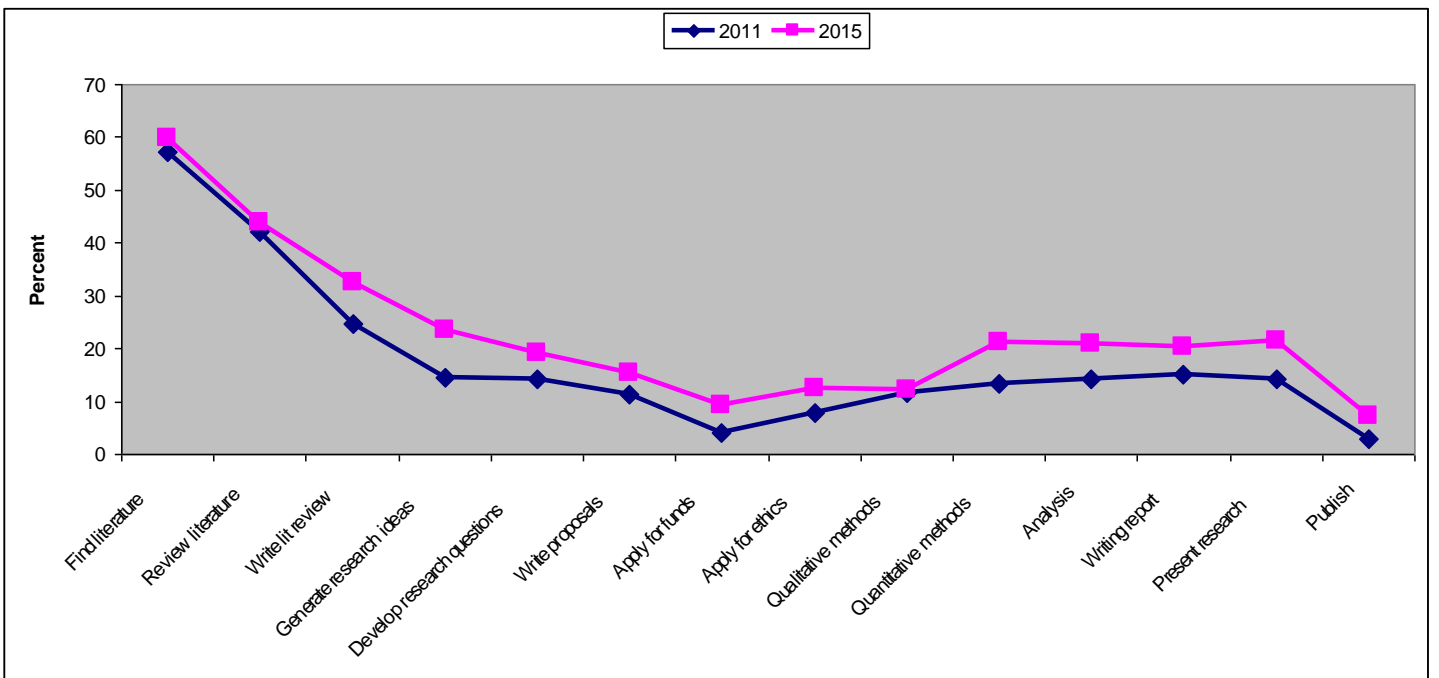

Figure 1: Research experience represented graphically across the research activity continuum. The percentages shown are the sum of respondents who indicated they were "very" and "moderately" experienced.

Research experience increased from 2011 to 2015 across many of the specified research tasks. More respondents indicated higher levels of experience for: generating research ideas $(p=0.018)$; developing questions $(p=0.028)$; writing proposals $(p=0.005)$; applying for grants $(p=0.027)$; writing ethics applications $(0.014)$; quantitative research methods $(p=0.004)$; analysing data $(p=0.006)$ and publishing $(p=0.004)$. The differences were mostly responses moving from lower (some or little) to higher (moderate) levels of experience (Table 2). 
Table 2: Percent of respondents who indicated they were very experienced, moderately experienced, had some experience, little experience or no experience in research for the respective 2011 and 2015 surveys.

\begin{tabular}{|c|c|c|c|c|c|c|c|}
\hline Research activity & Year & $\begin{array}{l}\text { Very } \\
\text { Exp }\end{array}$ & $\begin{array}{l}\text { Mod } \\
\text { Exp }\end{array}$ & $\begin{array}{l}\text { Some } \\
\text { Exp }\end{array}$ & Little Exp & $\begin{array}{l}\text { No } \\
\text { Exp. }\end{array}$ & $P$ value \\
\hline \multirow[t]{2}{*}{ Find literature } & $2011(n=241)$ & 12.9 & 44.4 & 31.1 & 10.8 & 0.8 & \multirow[t]{2}{*}{0.780} \\
\hline & $2015(n=207)$ & 12.1 & 47.8 & 29.0 & 10.1 & 1.0 & \\
\hline \multirow[t]{2}{*}{ Review literature } & $2011(n=240)$ & 5.4 & 36.7 & 31.3 & 22.1 & 4.6 & \multirow[t]{2}{*}{0.153} \\
\hline & $2015(n=207)$ & 8.2 & 35.7 & 39.1 & 13.5 & 3.4 & \\
\hline \multirow[t]{2}{*}{ Write literature review } & $2011(n=239)$ & 3.8 & 20.9 & 40.2 & 21.8 & 13.4 & \multirow[t]{2}{*}{0.077} \\
\hline & $2015(n=207)$ & 4.8 & 27.5 & 37.2 & 22.7 & 7.7 & \\
\hline \multirow{2}{*}{$\begin{array}{l}\text { Generate research } \\
\text { ideas* }\end{array}$} & $2011(n=240)$ & 2.1 & 12.5 & 41.3 & 31.7 & 12.5 & \multirow[t]{2}{*}{0.018} \\
\hline & $2015(n=204)$ & 3.9 & 19.6 & 38.7 & 30.9 & 6.9 & \\
\hline \multirow[t]{2}{*}{ Developing questions ${ }^{*}$} & $2011(n=241)$ & 2.1 & 12.0 & 36.1 & 33.6 & 16.2 & \multirow[t]{2}{*}{0.028} \\
\hline & $2015(n=207)$ & 4.8 & 14.5 & 39.6 & 30.0 & 11.1 & \\
\hline \multirow[t]{2}{*}{ Writing proposals* } & $2011(n=240)$ & 0.8 & 10.4 & 22.5 & 27.5 & 38.8 & \multirow[t]{2}{*}{0.005} \\
\hline & $2015(n=207)$ & 3.9 & 11.6 & 31.4 & 24.2 & 29.0 & \\
\hline \multirow[t]{2}{*}{ Applying for funds* } & $2011(n=240)$ & 0.4 & 3.8 & 11.7 & 22.1 & 62.1 & \multirow[t]{2}{*}{0.027} \\
\hline & $2015(n=207)$ & 1.4 & 7.7 & 13.5 & 24.2 & 53.1 & \\
\hline \multirow{2}{*}{$\begin{array}{l}\text { Writing ethics } \\
\text { applications }{ }^{*}\end{array}$} & $2011(n=240)$ & 0.4 & 7.5 & 16.7 & 22.9 & 52.5 & \multirow[t]{2}{*}{0.014} \\
\hline & $2015(n=207)$ & 3.4 & 9.2 & 31.7 & 21.7 & 44.0 & \\
\hline \multirow[t]{2}{*}{ Qualitative methods } & $2011(n=240)$ & 2.1 & 9.6 & 22.1 & 33.8 & 32.5 & \multirow[t]{2}{*}{0.107} \\
\hline & $2015(n=206)$ & 1.5 & 10.7 & 30.6 & 30.1 & 27.2 & \\
\hline \multirow[t]{2}{*}{ Quantitative methods* } & $2011(n=239)$ & 1.7 & 11.7 & 25.1 & 30.1 & 31.4 & \multirow[t]{2}{*}{0.004} \\
\hline & $2015(n=207)$ & 3.4 & 17.9 & 30.0 & 27.1 & 21.7 & \\
\hline \multirow[t]{2}{*}{ Analyse data* } & $2011(n=240)$ & 2.5 & 11.7 & 29.6 & 31.3 & 25.0 & \multirow[t]{2}{*}{0.006} \\
\hline & $2015(n=207)$ & 3.4 & 17.4 & 34.3 & 29.5 & 15.5 & \\
\hline \multirow[t]{2}{*}{ Write reports } & $2011(n=240)$ & 2.5 & 12.5 & 22.5 & 28.7 & 33.8 & \multirow[t]{2}{*}{0.063} \\
\hline & $2015(n=207)$ & 4.3 & 15.9 & 27.5 & 24.2 & 28.0 & \\
\hline \multirow[t]{2}{*}{ Conferences } & $2011(n=241)$ & 3.3 & 10.8 & 19.9 & 27.4 & 38.6 & \multirow[t]{2}{*}{0.105} \\
\hline & $2015(n=206)$ & 5.3 & 16.0 & 19.4 & 25.7 & 33.5 & \\
\hline \multirow[t]{2}{*}{ Publish* } & $2011(n=237)$ & 0.4 & 2.5 & 11.0 & 16.5 & 69.6 & \multirow[t]{2}{*}{0.011} \\
\hline & $2015(n=207)$ & 2.4 & 4.8 & 15.0 & 18.4 & 59.4 & \\
\hline
\end{tabular}

Significance was assumed if the p value was less than 0.05 (*Indicates significance). The number of respondents is shown in the Year column.

Need for research support

Significant differences were seen in the need for support in all questions except applying for funds, qualitative methods, quantitative methods and publishing (Table 3). The difference was manifest as a greater proportion of respondents indicating they required higher levels of support to start research in 2015 compared to 2011.

Table 3: Percent of respondents who indicated they required a lot of, moderate, some, little or no support to conduct research for the respective 2011 and 2015 surveys.

\begin{tabular}{|l|l|c|c|c|c|c|c|}
\hline Research activity & Year & $\begin{array}{l}\text { A lot of } \\
\text { support }\end{array}$ & $\begin{array}{l}\text { Moderate } \\
\text { support }\end{array}$ & $\begin{array}{l}\text { Some } \\
\text { support }\end{array}$ & $\begin{array}{l}\text { Little } \\
\text { support }\end{array}$ & $\begin{array}{l}\text { No } \\
\text { support }\end{array}$ & P value \\
\hline Find literature & 2011 & 6.7 & 13.4 & 33.6 & 37.0 & 9.2 & $<0.001$ \\
& 2015 & 8.7 & 39.4 & 30.8 & 20.2 & 1.0 & \\
\hline \multirow{2}{*}{ Review literature* } & 2011 & 11.1 & 17.3 & 39.2 & 27.4 & 5.1 & $<0.001$ \\
\cline { 2 - 7 } & 2015 & 14.2 & 45.3 & 23.6 & 17.0 & 0 & \\
\hline Write literature review $^{*}$ & 2011 & 15.5 & 21.4 & 33.2 & 25.2 & 4.6 & $<0.001$ \\
\hline
\end{tabular}




\begin{tabular}{|c|c|c|c|c|c|c|c|}
\hline & 2015 & 18.1 & 50.5 & 18.1 & 12.4 & 1.0 & \\
\hline \multirow[t]{2}{*}{ Generate research ideas ${ }^{*}$} & 2011 & 14.3 & 28.3 & 38.4 & 17.3 & 1.7 & \multirow[t]{2}{*}{$<0.001$} \\
\hline & 2015 & 15.9 & 54.2 & 19.6 & 10.3 & 0 & \\
\hline \multirow[t]{2}{*}{ Developing questions* } & 2011 & 17.2 & 31.1 & 32.8 & 16.8 & 2.1 & \multirow[t]{2}{*}{$<0.001$} \\
\hline & 2015 & 17.0 & 57.5 & 17.0 & 7.5 & 0.9 & \\
\hline \multirow{2}{*}{ Writing proposals* } & 2011 & 28.4 & 32.2 & 29.2 & 9.3 & 0.8 & \multirow[t]{2}{*}{0.003} \\
\hline & 2015 & 31.8 & 53.3 & 7.5 & 7.5 & 0 & \\
\hline \multirow[t]{2}{*}{ Applying for funds } & 2011 & 41.6 & 36.6 & 14.7 & 5.9 & 1.3 & \multirow[t]{2}{*}{0.130} \\
\hline & 2015 & 44.9 & 40.2 & 10.3 & 3.7 & 0.9 & \\
\hline \multirow[t]{2}{*}{ Writing ethics applications* } & 2011 & 39.4 & 30.9 & 18.6 & 9.7 & 1.3 & \multirow[t]{2}{*}{0.027} \\
\hline & 2015 & 44.4 & 38.0 & 12.0 & 4.6 & 0.9 & \\
\hline \multirow[t]{2}{*}{ Qualitative methods } & 2011 & 28.3 & 31.2 & 26.2 & 12.7 & 1.7 & \multirow[t]{2}{*}{0.140} \\
\hline & 2015 & 21.7 & 51.9 & 18.9 & 7.5 & 0 & \\
\hline \multirow[t]{2}{*}{ Quantitative methods } & 2011 & 26.7 & 32.2 & 27.1 & 13.1 & 0.8 & \multirow[t]{2}{*}{0.081} \\
\hline & 2015 & 26.4 & 45.3 & 19.8 & 8.5 & 0 & \\
\hline \multirow[t]{2}{*}{ Analyse data* } & 2011 & 27.4 & 32.5 & 27.0 & 12.2 & 0.8 & \multirow[t]{2}{*}{0.013} \\
\hline & 2015 & 29.0 & 46.7 & 19.6 & 4.7 & 0 & \\
\hline \multirow[t]{2}{*}{ Write reports* $^{\star}$} & 2011 & 26.9 & 29.9 & 28.6 & 13.7 & 0.9 & \multirow[t]{2}{*}{0.028} \\
\hline & 2015 & 25.2 & 51.4 & 14.0 & 8.4 & 0.9 & \\
\hline \multirow[t]{2}{*}{ Conferences* $^{*}$} & 2011 & 26.7 & 26.3 & 28.4 & 14.8 & 3.8 & \multirow[t]{2}{*}{0.034} \\
\hline & 2015 & 26.4 & 42.5 & 18.9 & 11.3 & 0.9 & \\
\hline \multirow[t]{2}{*}{ Publish } & 2011 & 51.1 & 28.1 & 14.5 & 6.0 & 0.4 & \multirow[t]{2}{*}{0.241} \\
\hline & 2015 & 48.6 & 40.2 & 7.5 & 2.8 & 0.9 & \\
\hline
\end{tabular}

Significance was assumed if the $p$ value was less than 0.05 (*Indicates significance).

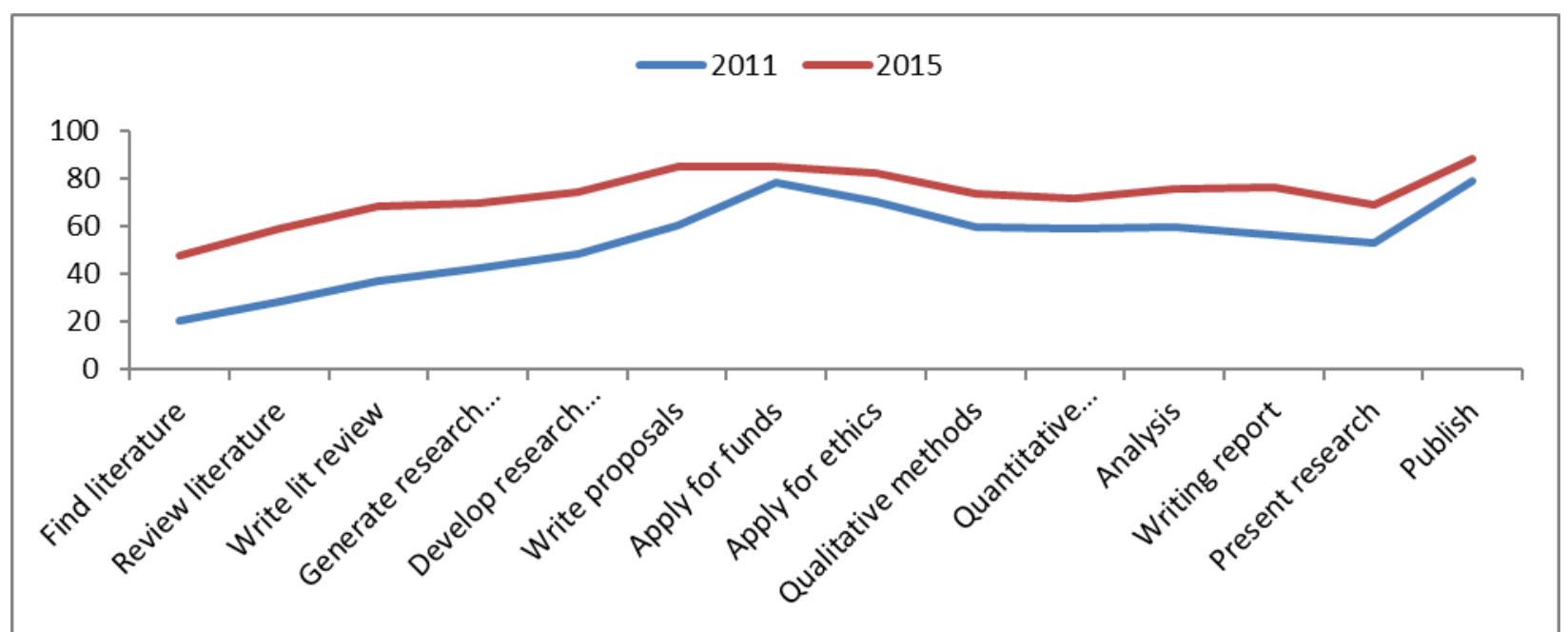

Figure 2: The comparison of research support needs to start research between 2011 and 2015 represented graphically across the research activity continuum. The percentages shown are the sum of responses for 'a lot' and 'moderate' support.

\section{Enablers and barriers}

Identified enablers and barriers to allied health research remained mostly unchanged between 2011 and 2015 (Table 4). However, significant differences were noted between the two surveys in response to questions about relevance to job, confidence with writing and time for research. In each case, the responses indicated a higher level of agreement. For example, $14.4 \%$ of respondents strongly agreed research was relevant to their job in 2011 whereas $29.9 \%$ strongly agreed it was relevant to their job in 2015. Similar increases were seen in response to the questions about confidence with writing and time for research. 
Table 4: Responses to the survey questions asking about enablers and barriers to conduct research with $p$ values relating to the comparison between 2011 and 2015

\begin{tabular}{|c|c|c|c|c|c|c|c|}
\hline Research activity & Year & $\begin{array}{l}\text { Strongly } \\
\text { agree }\end{array}$ & Agree & Neither & Disagree & $\begin{array}{l}\text { Strongly } \\
\text { disagree }\end{array}$ & $P$ value \\
\hline \multirow{2}{*}{$\begin{array}{l}\text { Research is relevant to my } \\
\text { job }\end{array}$} & 2011 & 14.4 & 56.3 & $\begin{array}{l}18.3 \\
\end{array}$ & 8.7 & 2.2 & \multirow[t]{2}{*}{$<0.001$} \\
\hline & 2015 & 29.9 & 46.0 & 20.9 & 1.4 & 1.9 & \\
\hline \multirow{2}{*}{$\begin{array}{l}\text { I don't have topic for } \\
\text { research }\end{array}$} & 2011 & 5.7 & 22.9 & 28.2 & 35.7 & 7.5 & \multirow[t]{2}{*}{0.393} \\
\hline & 2015 & 11.0 & 29.2 & 25.8 & 23.4 & 10.5 & \\
\hline \multirow{2}{*}{$\begin{array}{l}\text { My line manager is } \\
\text { supportive of research }\end{array}$} & 2011 & 11.0 & 48.5 & 30.4 & 7.5 & 2.6 & \multirow[t]{2}{*}{0.148} \\
\hline & 2015 & 16.7 & 48.6 & 23.3 & 7.1 & 4.3 & \\
\hline \multirow{2}{*}{$\begin{array}{l}\text { The thought of research } \\
\text { makes me anxious }\end{array}$} & 2011 & 9.3 & 38.3 & 21.1 & 26.0 & 5.3 & \multirow[t]{2}{*}{0.467} \\
\hline & 2015 & 11.4 & 32.9 & 25.7 & 22.9 & 7.1 & \\
\hline \multirow{2}{*}{$\begin{array}{l}\text { My colleagues are } \\
\text { supportive }\end{array}$} & 2011 & 6.1 & 47.8 & 38.6 & 6.6 & 0.9 & \multirow[t]{2}{*}{0.717} \\
\hline & 2015 & 9.0 & 49.8 & 34.1 & 4.7 & 2.4 & \\
\hline \multirow{2}{*}{$\begin{array}{l}\text { There is not enough } \\
\text { statistical support }\end{array}$} & 2011 & 5.3 & 21.2 & 53.1 & 17.3 & 3.1 & \multirow[t]{2}{*}{0.819} \\
\hline & 2015 & 4.7 & 18.9 & 54.7 & 18.4 & 3.3 & \\
\hline \multirow{2}{*}{$\begin{array}{l}\text { Funding is available for me } \\
\text { to do research }\end{array}$} & 2011 & 0 & 26.3 & 53.1 & 14.5 & 6.1 & \multirow[t]{2}{*}{0.235} \\
\hline & 2015 & 1.9 & 27.1 & 53.8 & 12.4 & 4.8 & \\
\hline \multirow{2}{*}{$\begin{array}{l}\text { Research is part of work } \\
\text { plan }\end{array}$} & 2011 & 4.9 & 39.1 & 34.2 & 18.2 & 3.6 & \multirow[t]{2}{*}{0.154} \\
\hline & 2015 & 6.7 & 41.9 & 31.0 & 15.2 & 5.2 & \\
\hline \multirow{2}{*}{$\begin{array}{l}\text { We are too short staffed for } \\
\text { me to do research }\end{array}$} & 2011 & 20.2 & 29.8 & 34.2 & 11.8 & 3.9 & \multirow[t]{2}{*}{0.083} \\
\hline & 2015 & 24.6 & 31.3 & 31.3 & 10.9 & 1.9 & \\
\hline \multirow[t]{2}{*}{ I am not a confident writer } & 2011 & 1.8 & 17.3 & 28.3 & 46.0 & 6.6 & \multirow[t]{2}{*}{$<0.001$} \\
\hline & 2015 & 6.7 & 30.5 & 29.0 & 27.1 & 6.7 & \\
\hline \multirow{2}{*}{$\begin{array}{l}\text { I do not have enough time } \\
\text { to do research }\end{array}$} & 2011 & 32.4 & 41.3 & 17.8 & 6.7 & 1.8 & \multirow[t]{2}{*}{0.004} \\
\hline & 2015 & 42.2 & 37.4 & 15.6 & 3.8 & 0.9 & \\
\hline
\end{tabular}

\section{Benefits of research}

The benefit of research from the perspective of the AHPs was service improvement rather than personal improvement (Figure 3). Most respondents strongly agreed the benefits of research were to make a difference in clinical care (56.8\%) and evaluate their service (52.6\%). To a lesser extent, respondents strongly agreed the benefits of research were: fill a knowledge gap (45.8\%); further their profession (41.3\%); for professional development (38.7\%); and further their qualifications (33.5\%). 


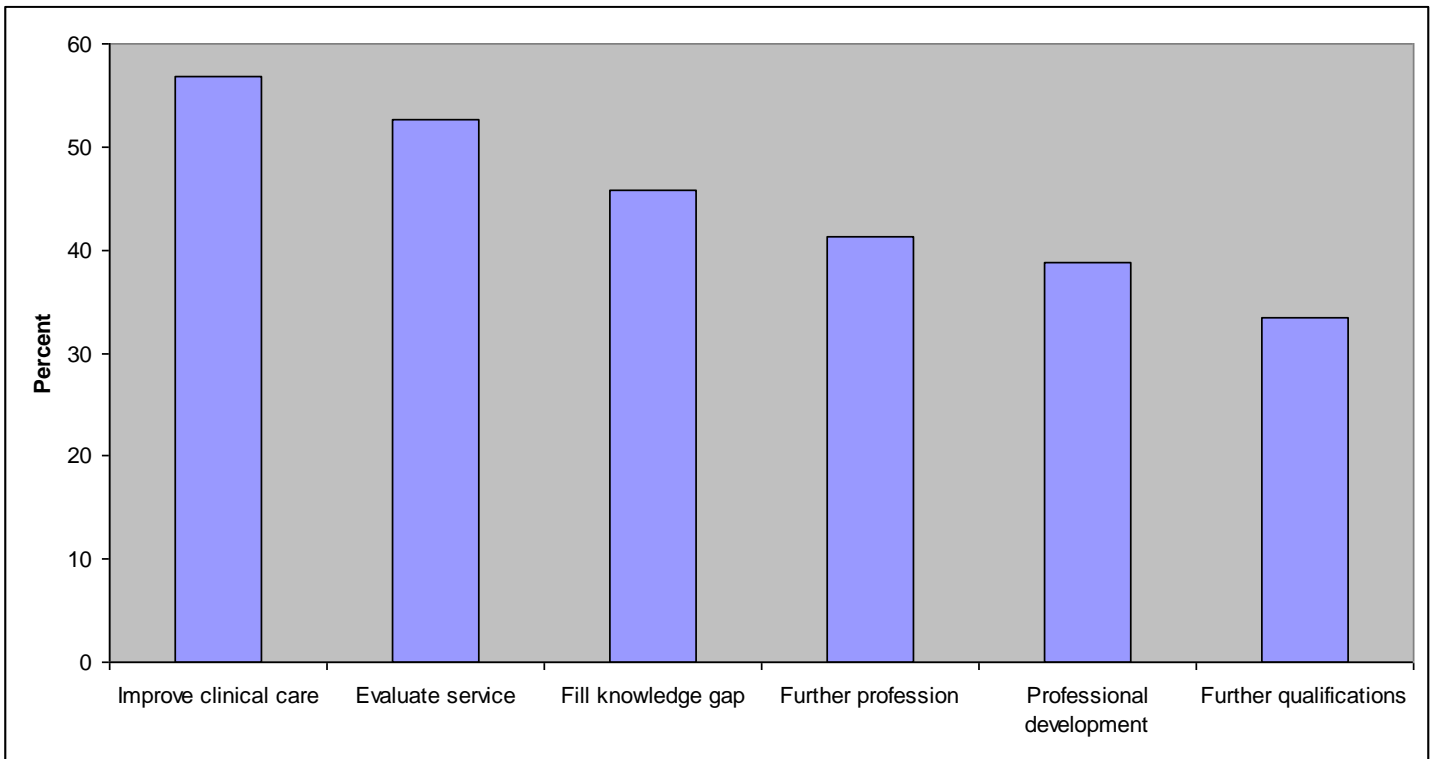

Figure 3: Proportion of AHPs that "strongly agreed" to the question "What is the benefit of research?" where the above options were listed for participants to: strongly agree, agree, neither agree nor disagree, disagree, or strongly disagree.

\section{DISCUSSION}

This study demonstrated an increase in AHP research experience between the 2011 and 2015 surveys. It also showed an increased need for research support for the listed activities over the same period. The observed increase in experience was evident in most activities on the research continuum where activities on the left of the continuum were associated with 'using' research and on the right associated with 'producing' research. ${ }^{6}$ The activities listed on the continuum were developed previously. ${ }^{8}$ The exception to the increase in activity is the low experience reported with traditional research capacity measures (i.e. grant applications and peer reviewed publications). Using traditional measures, the increase in research experience demonstrated by AHPs in this study would not be detected. Nevertheless, there was a significant increase in AHPs experience in research over the four-year period. It has been suggested that traditional RCB outcome measures, while important, are not as relevant in healthcare contexts. ${ }^{2}$ Therefore, to measure RCB of AHPs within healthcare, we recommend expanding traditional RCB outcomes to include changes in capacity and culture at individual, team and organisation levels. ${ }^{9}$

The increased research activity by AHPs demonstrated in this study may contribute to improved organisational research culture. Research culture relates to the research environment at the organisation level and is contributed to by research competencies of individuals. ${ }^{10,11}$ To build organisational research capacity, multilevel approaches are required, such as partnerships with external academics, whole of organisation leadership and appropriate personnel. ${ }^{12}$ These key themes have been echoed by other researchers and are implemented at this study site. ${ }^{13}$ For example, the local RCB efforts have benefited from the introduction of the RF via the state-wide EBA. The organisation has built research capacity by establishing a research support unit, opening applications for internal grant funding to nurses and AHPs, employing a Director of Research, and approving funds for research office space. This top-down approach at state and organisation level may complement the bottom-up approach implemented by the RF to build research capacity among AHPs and, in turn, change organisational research culture.

The observed increased need for research support in 2015 compared to 2011 was contrary to expectation. We anticipated research support needs would decrease between 2011 and 2015 rationalising that as AHPs became more experienced in research they would require less support. However, respondents indicated a higher level of support need in all research activities in 2015 compared to 2011. The highest need for support in both surveys was for publishing. Further research is needed to tease out the rationale for the high support needed for publishing, but the result may help explain the low publication rate of AHPs. A similar higher level of support need was previously detected after a RCB initiative had commenced among podiatrists. ${ }^{14}$

Both intrinsic and extrinsic motivators are required to establish a successful clinician-researcher career..$^{15}$ Results from this study imply many AHPs possess intrinsic motivators. Intrinsic motivators, such as a personal desire to improve 
health services, were demonstrated by a high proportion of AHPs who indicated the benefit of research was to 'improve clinical care'. Given this finding, it is evident that traditional approaches used to measure research impact may be insufficient in this setting and the efficiency and equity of research outcomes as well as patient satisfaction and quality of life outcomes should also be evaluated as important research outcomes. ${ }^{16}$ This is becoming an important consideration in clinical research with the current focus on performance-based research funding and the duty to maintain patient care as the primary endpoint in research endeavours.

Additionally, this study suggests extrinsic motivators such as those provided by the RF at organisational level are also working. ${ }^{15}$ However, lack of time was cited by most AHPs as a barrier to research. To overcome the barrier of time, AHPs can apply for grants to backfill their clinical positions with an uncertain promise of success. Alternatively, HHSs could establish clinician-researcher career pathways in a similar model to the clinical educator already established in Queensland Health $(\mathrm{QH})$. Although conducting research was written into the role description of HPs through the EBA, there are currently no defined clinical-researcher career pathways in allied health within QH. RCB cannot be divorced from consideration of the career trajectories of educational researchers. ${ }^{17}$ Therefore, consideration of a dedicated clinical researcher role in health services may escalate the capacity building process within allied health to increase outcomes using traditional measures such as publishing. It has already been demonstrated that better outcomes for research capacity investment will be realised if quarantined time is given to AHPs who are already motivated to conduct research. ${ }^{4}$

The 2015 survey introduced a new question asking AHPs to indicate the benefits of research. Over $50 \%$ of respondents chose 'to improve service delivery' and 'evaluate service' suggesting AHPs have an altruistic perception of the role of research in healthcare contexts. This altruistic perception of research by AHPs presents problems in how to approach research given many of their roles are to deliver complex interventions, in multidisciplinary teams with predominantly holistic rather than biological or functional outcomes. ${ }^{18}$ Clinicians highlighted a need for relevant and applicable research suggesting AHP research align with Health Services Research (HSR) with its various methodologies to measure efficiency, outcomes and policy and practice change. ${ }^{19}$ This alignment is evidenced by cost efficiencies from delegation, and health care pathways. ${ }^{20,21}$ These studies support the notion that research interest by clinicians is necessary to challenge and inform their clinical practice skills through clinical research. ${ }^{22}$ In short, it suggests allied health have enormous potential to contribute to improve efficiency, and outcomes in health care.

A limitation of this study was that people who were interested in the topic were more likely to have responded to the electronic surveys. Based on this assumption, we considered many of the same AHPs responded to both surveys. While this meant the study likely experienced a positive bias in the results, it may also reflect an actual change of AHPs who were interested in becoming involved and were commencing their research journey between 2011 and 2015.

The strengths of this research include the inclusion of many allied health disciplines, the inclusion of both hospital and community based AHPs and the inclusion of some key RCB domains in the follow-up survey.

\section{CONCLUSION}

This study demonstrated AHPs are becoming increasingly experienced in research but not yet on the scale of traditional RCB measures. The introduction of researcher-clinician career pathways may overcome the lack of time cited by AHPs as a barrier and may elevate AHP research outputs to the level measured by traditional RCB outcomes. Finally, this study suggests AHPs research is more aligned to HSR to improve clinical practice and/or patient outcomes.

\section{REFERENCES}

1. Hulcombe J, Sturgess J, Souvlis T, Fitzgerald C. An approach to building research capacity for health practitioners in a public health environment: an organisational perspective. Aust Health Rev. 2014;38:252-8. [PMID: 24785693]

2. Cooke J. A framework to evaluate research capacity building in health care. BMC Fam Pract. 2005;6(44):1-6. [PMID: 16253133]

3. Condell SL, Begley C. Capacity building: a concept analysis of the term applied to research. Int J Nurs Pract. 2007 Oct;13(5):268-75. [PMID: 17883712]

(C) Internet Journal of Allied Health Sciences and Practice, 2018 
4. Pager S, Holden L, Golenko X. Motivators, enablers and barriers to building allied health research capacity. $J$ Multidiscip Healthc. 2012;5:53-9. [PMID: 22396626]

5. Pain T, Plummer D, Pighills A, Harvey D. Comparison of research experience and support needs of rural versus regional allied health professionals. Aust J Rural Health. 2015 Oct;23(5):277-85. [PMID: 26381792]

6. Pighills AC, Plummer D, Harvey D, Pain T. Positioning occupational therapy as a discipline on the research continuum: results of a cross-sectional survey of research experience. Aust Occup Ther J. 2013 Aug;60(4):241-51. [PMID: 23888974]

7. Harvey D, Plummer D, Pighills A, Pain T. Practitioner research capacity: a survey of social workers in northern Queensland. Aust Social Work. 2013;66(4):540-54.

8. Smith H, Wright D, Morgan S, Dunleavey J. The 'Research Spider': a simple method of assessing research experience. Prim Health Care Res Dev. 2002;3:139-40.

9. Holden L, Pager S, Golenko X, Ware RS. Validation of the research capacity and culture (RCC) tool: measuring RCC at individual, team and organisation levels. Aust J Prim Health. 2012;18(1):62-7. [PMID: 22394664]

10. Wagner AK, McElligott J, Wagner EP 2nd, Gerber LH. Measuring rehabilitation research capacity: report from the AAPM \& R Research Advisory Committee. Am J Phys Med Rehabil. 2005 Dec;84(12):955-68. [PMID: 16327412]

11. Bailey J, Veitch C, Crossland L, Preston R. Developing research capacity building for Aboriginal \& Torres Strait Islander health workers in health service settings. Rural Remote Health. 2006;6(4):556. [PMID: 17187447]

12. Murphy K, Stockton D, Kolbe A, Hulme-Chambers A, Smythe G. Building research capacity in a regional Australian Health Service: a management strategy analysis. Asia Pacific J Health Management. 2015;10(1):14-22.

13. Golenko X, Pager S, Holden L. A thematic analysis of the role of the organisation in building allied health research capacity: a senior manager's perspective. BMC Health Serv Res. 2012 Aug 27;12:276. [PMID: 22920443]

14. Lazzarini PA, Geraghty J, Kinnear EM, Butterworth M, Ward D. Research capacity and culture in podiatry: early observations within Queensland Health. J Foot Ankle Res. 2013 Jan 9;6(1):1. [PMID: 23302627]

15. Harvey D, Plummer D, Nielsen I, Adams R, Pain T. Becoming a clinician-researcher in allied health. Aust Health Rev. 2016 Nov;40(5):562-9. [PMID: 26803541]

16. Hinrichs-Krapels S, Grant J. Exploring the effectiveness, efficiency and equity (3e's) of research and research impact assessment. Palgrave Communications. 2016; 2:16090 doi: 10.1057/palcomms.2016.90.

17. Rees G, Baron S, Boyask R, Taylor C. Research-capacity building, professional learning and the social practices of educational research. British Edu Res J. 2007;33(5):761-79.

18. Pickstone C, Nancarrow S, Cooke J, Vernon W, Mountain G, Boyce R, Campbell J. Building research capacity in the allied health professions. Evidence Policy. 2008;4(1):75-91.

19. Sandberg JG, Johnson LN, Robila M, Miller RB. Clinician identified barriers to clinical research. J Marital Fam Ther. 2002 Jan;28(1):61-7. [PMID: 11813368]

20. Somerville L, Davis A, Terrill D, Austin N, Phillip K. Building allied health workforce capacity: a strategic approach to workforce innovation. Aust Health Rev. 2015;39:264-70

21. Standfield L, Comans T, Raymer M, O'Leary S, Morretto N, Scuffham P. The efficiency of increasing the capacity of physiotherapy screening clinics or traditional medical services to address unmet demand in orthopaedic outpatients:

(C) Internet Journal of Allied Health Sciences and Practice, 2018 
A practical application of discrete event simulation with dynamic queuing. Appl Health Econ Health Policy. 2016;14(4):479-91. [PMID: 27116389]

22. Stephens D, Taylor NF, Leggat SG. Research experience and research interests of allied health professionals. J Allied Health. 2009;38(4):e107-11. [PMID: 20011811] 